\title{
ULTRASTRUCTURAL TAIL DEFECTS IN THE SPERMATOZOA FROM TWO MEN ATTENDING A SUBFERTILITY CLINIC
}

\author{
A. ROSS, SHEILA GHRISTIE AND P. EDMOND* \\ Medical Research Council, Clinical and Population Cytogenetics Unit, \\ Western General Hospital, Edinburgh, and \\ *Department of Urology, The Royal Infirmary, Edinburgh
}

(Received 31st December 1971)

\begin{abstract}
Summary. Similar ultrastructural defects were found in the spermatozoa of two oligospermic men attending a subfertility clinic.

The majority of spermatozoa had a mid-piece of grossly abnormal morphology and the diameter of the tail was increased, due to an excess of outer-sheath fibres. Extra, as well as missing, axial-filament fibres were also seen. In both cases, only a very small proportion of the spermatozoa were motile.

A testicular biopsy was performed on each man and although the histological appearance was normal, abnormal spermatozoa were seen in thin sections examined by electron microscopy.
\end{abstract}

\section{INTRODUCTION}

There are a number of reports on animals with structural defects of spermatozoa which affect fertility. A 'knobbed' acrosomal defect has been described in the spermatozoa of bulls by Hancock (1953) and Blom \& Birch-Andersen (1962) and in the spermatozoa from boars (Bane, 1961). An abnormality of the spermatozoa from some Guernsey bulls known as the 'decapitate defect' in which the head and tail become separated was shown to be associated with an ultrastructural abnormality in the neck region (Blom \& Birch-Andersen, 1970). Abnormal spermatozoa, showing what has been described as the 'Dag defect', have been recorded in three Danish Jersey Bulls (Blom, 1966; KoefoedJohnsen \& Pedersen, 1971); the abnormal spermatozoa in these animals showed a folding of the main-piece over the mid-piece, giving the impression of a short tail. A further ultrastructural defect was described by Blom \& Birch-Andersen (1968) in the spermatozoa from five sterile Fresian bulls. The spermatozoa from these animals had a 'pseudo-droplet' defect showing a rounding or elongated thickening of the mid-piece. Blom (1959) has also reported a rarer sperm abnormality in two secondarily sterile RDM (Rodt Dansk Malkekveag) bulls where between 15 and $49 \%$ of the spermatozoa had a mid-piece shaped like a corkscrew and these spermatozoa were immotile. 
Recently, Aughey \& Renton (1971) described a structural abnormality in spermatozoa from a dog which had a lowered fertility. Electron microscope examination showed a thickened mid-piece due to the presence of either a cytoplasmic droplet or pseudo-droplet similar to that described by Blom \& Birch-Andersen (1968) in bulls.

Rajasekarasetty (1954) has reported that in certain mouse genotypes, 14 to $58 \%$ of the spermatozoa have abnormalities involving the sperm nucleus and acrosome.

In the case of man, there are very few reports which describe specific ultrastructural defects of the spermatozoa affecting fertility. Kagan (1963) examined spermatozoa from two oligospermic men by electron microscopy and showed, in both cases, that the heads of the spermatozoa contained coarse chromatin indicating immaturity. The same author described a case of necrospermia in which the spermatozoa were immotile and showed coarse chromatin and absent tail fibres when examined by the electron microscope. Ross, Christie \& Kerr (1971) described a specific ultrastructural tail defect in spermatozoa from a subfertile male in which the mid-piece was elongated and the outer-sheath fibres were missing. A similar ultrastructural abnormality of the spermatozoa was found in a subfertile male by Pedersen, Rebbe \& Hammen (1971).

The two patients reported here, as well as the one previously reported by Ross et al. (1971), were found during routine examination of males attending a subfertility clinic. These cases all have defects of the tail, greatly reduced motility and an abnormal morphology which was readily detected by light microscopy during routine seminal analysis.

\section{MATERIALS AND METHODS}

Light microscope seminal analysis was carried out on part of the fresh ejaculated specimens obtained at the subfertility clinic and the remainder of each specimen was processed for electron microscopy by a method described previously (Ross et al., 1971). Testicular biopsies were obtained from both men and the material examined by histological and electron microscope techniques.

To determine if the ultrastructural defects were associated with a chromosome aberration, peripheral blood was obtained to examine the mitotic chromosome complement, and analysis of the meiotic chromosomes was made on part of the testicular biopsy material.

\section{RESULTS}

Patient A was a 23-year-old male who presented at the subfertility clinic after 11 months of marriage. Contraception had not been employed, and the physical status of his wife was normal. The patient was born in East Africa of Indian parents and was the youngest of four sons. Two of his elder brothers had recently married but have not yet had children while the remaining brother is unmarried. The patient was physically unremarkable with the exception that his right testis was small. His secondary sexual characteristics were normal. 
Seminal analysis with the light microscope on four occasions (Table 1) showed a sperm density which varied between $<1$ and $14 \times 10^{6}$ spermatozoa $/ \mathrm{ml}$ with a motility varying from 0 to $2 \%$. Haematoxylin-and-eosin-stained preparations showed the spermatozoa (Pl. 1, Fig. A) to be shorter than normal with an increase in diameter of the mid-piece and main-piece or with a thickened mid-piece and no main-piece. An occasional spermatozoon of normal length with a thickened mid-piece and a main-piece thinner than normal was seen as well as an occasional spermatozoon with a large cytoplasmic droplet and no tail.

Histological examination of the testis showed the seminiferous tubules to be normal and spermatogenesis to be active. In the interstitium, there was a slight increase in the number of Leydig cells and fibrocytes.

Examination of peripheral blood showed a normal 46,XY chromosome complement. The $\mathrm{Y}$ chromosome appeared large, being equal in size to an $\mathrm{E}$ group chromosome. However, this is regarded as a normal variation as $\mathrm{Y}$ chromosomes of this size are found in 2 to $3 \%$ of the population (Court Brown, Buckton, Jacobs, Tough, Kuenssberg \& Knox, 1966). A normal complement of twenty-three bivalents was found in meiotic preparations from the testis.

Table 1. Details of analyses of semen specimens from two infertile males

\begin{tabular}{l|c|l|c|c|c|c|c|c|c}
\hline & \multicolumn{4}{|c|}{ Patient A } & \multicolumn{6}{c}{ Patient B } \\
\cline { 2 - 9 } & $1 *$ & 2 & 3 & 4 & 1 & 2 & 3 & 4 & 5 \\
\hline Delay before examination (hr) & 2 & 0 & 0 & 0 & $1 \frac{1}{2}$ & 0 & 0 & 0 & $\frac{1}{2}$ \\
Volume (ml) & $2 \cdot 6$ & $1 \cdot 2$ & 3 & $1 \cdot 5$ & $4 \cdot 5$ & $11 \cdot 1$ & $2 \cdot 0$ & $5 \cdot 8$ & $4 \cdot 0$ \\
Count $\left(\times 10^{6} / \mathrm{ml}\right)$ & 14 & $0 \cdot 01$ & 6 & $5 \cdot 5$ & 12 & 14 & 25 & 11 & 11 \\
Total count $\left(\times 10^{6}\right)$ & $36 \cdot 4$ & $0 \cdot 012$ & $18 \cdot 0$ & $8 \cdot 25$ & $54 \cdot 0$ & $155 \cdot 4$ & $50 \cdot 0$ & $63 \cdot 8$ & $44 \cdot 0$ \\
Normal morphology $(\%)$ & 1 & 0 & 1 & 3 & 11 & 17 & 13 & 10 & 15 \\
Motility (\%) & 2 & 0 & 1 & 2 & 1 & 0 & 3 & 6 & 4 \\
\hline
\end{tabular}

* Specimen no.

Examination of whole mounts in the electron microscope shadowed with gold/palladium confirmed the light microscope findings but showed no demarcation between mid-piece and main-piece. In the majority of spermatozoa, the outer sheath did not extend along the whole length of the main-piece and in some cases, segments of the outer-sheath were missing (Pl. 1, Fig. B).

Examination of thin sections of spermatozoa in the electron microscope showed that approximately $12 \%$ of the heads contained coarse chromatin and $26 \%$ of the heads had either a degenerate or missing acrosome. The spermatozoa contained either a very short mid-piece with no obvious mitochondria (Pl. 1, Fig. C) or they had a mid-piece of normal length which contained abnormal mitochondria (Pl. 1, Fig. D). The mitochondrial cristae were not well formed and many of them contained a large electron-dense body. Occasionally, spermatozoa were seen with a large cytoplasmic droplet which contained a mass of disorganized material resembling outer-sheath fibres (P1. 1, Fig. E). 
The most striking abnormality in the majority of spermatozoa was the increase in the diameter of the main-piece due to an excess of outer-sheath fibres (Pl. 1, Fig. F). All cross-sections of the tail examined at various levels showed the thickened outer sheath (Pl. 1, Fig. G). In approximately $60 \%$ of the spermatozoa, the axial-filament complex showed the normal $9+9+2$ arrangement of fibres. However, in $40 \%$ of the spermatozoa the outer and inner fibres were present but the central two fibres were absent (Pl. 1, Fig. H).

Thin sections of testis were examined in the electron microscope. Cross sections through the tails of testicular spermatozoa showed them to have an increase in outer-sheath fibres with some of the spermatozoa missing the central fibres in the axial-filament complex (Pl. 3, Fig. A). In the spermatid, the developing acrosome was seen. The mitochondria appeared normal at this stage and did not contain electron-dense bodies (Pl. 3, Fig. B).

Patient B was a 29-year-old Caucasian male who presented for investigation after 5 years of marriage. Contraceptive measures had been employed for the first $2 \frac{1}{2}$ years of marriage and the physical status of his wife was normal. The patient had no history of significant illness, and was an only child. Clinical examination showed him to be unremarkable except for his testes. His left testis was small and atrophic associated with a significant varicocoele. The right testis was considerably enlarged but was of normal consistency. Investigation of the upper urinary outflow tract appeared normal. The varicocoele was treated by high ligation and a biopsy of the left testis was obtained at that procedure.

Seminal analysis by the light microscope on five occasions (Table 1) showed a sperm density between 11 and $25 \times 10^{6}$ spermatozoa $/ \mathrm{ml}$ with a motility ranging between 0 and $6 \%$. Haematoxylin-and-eosin-stained preparations showed a similar morphology to those of Patient A (Pl. 2, Fig. A).

Histological examination of the testis showed the seminiferous tubules to be cellular, with active spermatogenesis to the stage of spermatozoa. There was some thickening of the tunica propria but there was no hyalinization of the basement membrane and the interstitium appeared normal.

\section{EXPLANATION OF PLATE 1}

Fig. A. Light microscope photograph of spermatozoa from Patient A showing the typical abnormal morphology. $H$ and $E$.

Fig. B. Electron micrograph of gold/palladium shadowed spermatozoa from Patient A. Note the thickened outer sheath which in places is not continuous. No demarcation is seen between mid-piece and main-piece.

FrG. C. Longitudinal section of a spermatozoon from Patient A showing the shortened mid-piece area containing vesicles and the increase in fibres in the outer sheath.

FIg. D. Longitudinal section of a spermatozoon from Patient A showing a normal length mid-piece, and electron-dense bodies within the mitochondria.

Fig. E. Section through the head of a spermatozoon from Patient A, showing a cytoplasmic droplet containing a large amount of disorganized outer-sheath fibres.

FIG. F. Longitudinal section of the main-piece of a spermatozoon from Patient A showing the increased number of outer-sheath fibres.

Frg. G. Cross-section through the main-piece of a spermatozoon from Patient A, showing a normal $9+9+2$ axial filament complex and a thickened outer sheath.

FIG. $H$. Cross section through the main-piece of a spermatozoon from Patient $A$, showing the missing central two fibres and thickened outer sheath. 
PLATE 1

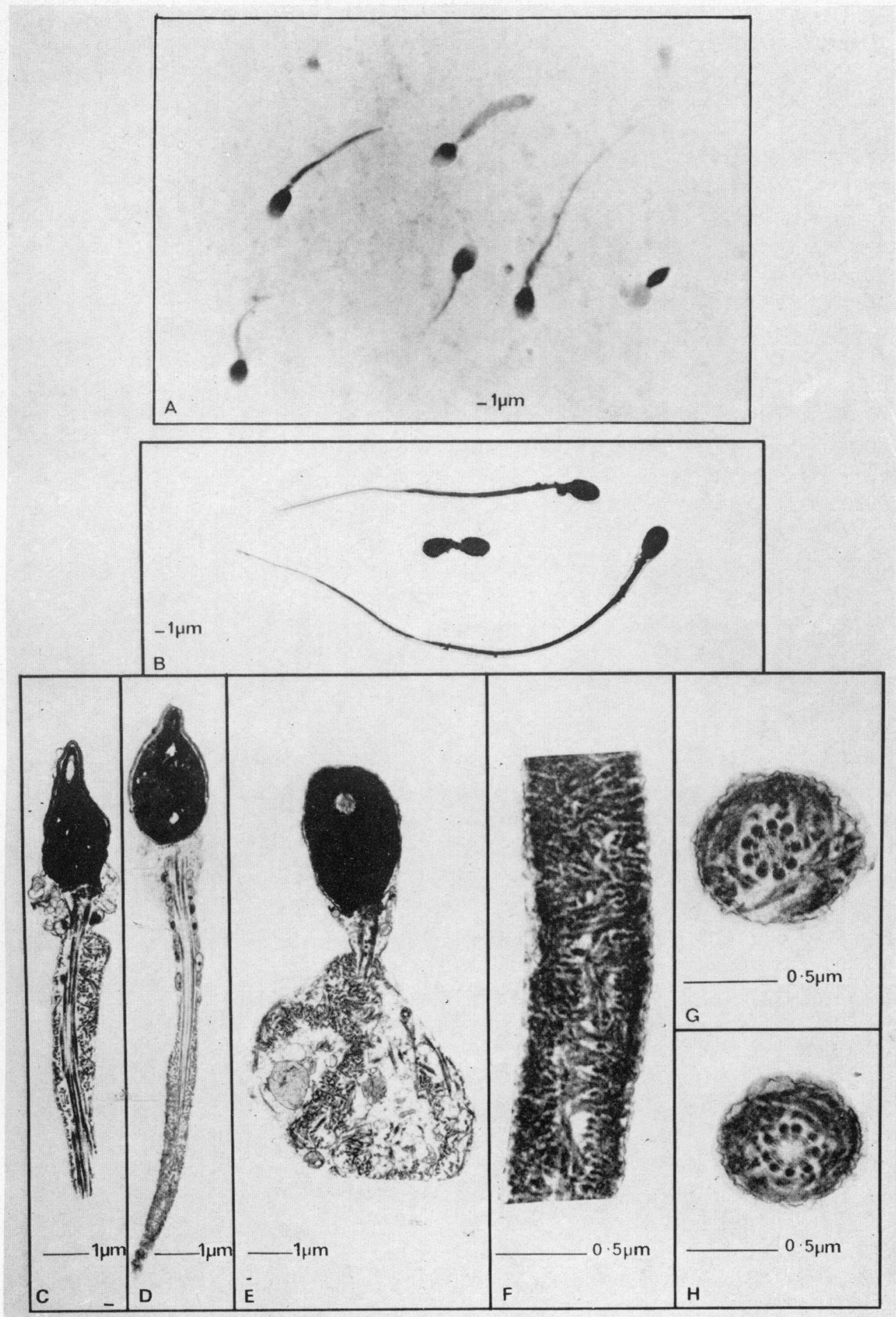

(Facing p. 246) 
PLATE 2

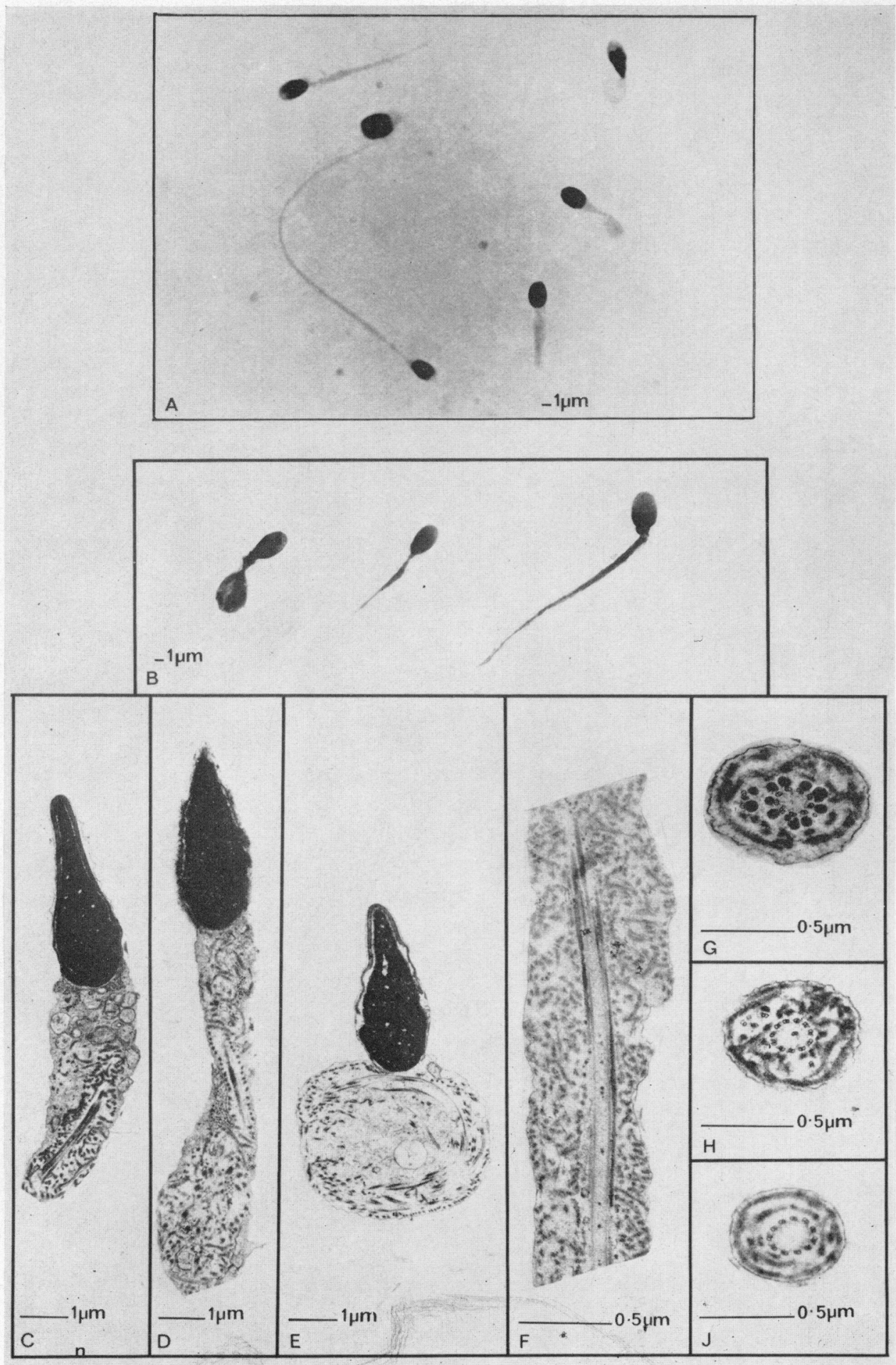

(Facing p. 247) 
Examination of peripheral blood showed a normal 46,XY chromosome complement. As no fresh testicular material was obtained from this case, examination of the meiotic chromosomes was not possible.

Whole mounts (Pl. 2, Fig. B) shadowed with gold/palladium and examined in the electron microscope showed spermatozoa with tails shorter than normal in length but with an increased diameter and with no clear demarcation between the mid-piece and the main-piece. Spermatozoa were also seen with a large cytoplasmic droplet and no tail.

In thin sections of spermatozoa in the electron microscope, $50 \%$ of the heads had a normal morphology and 30\% had a degenerate or missing acrosome while $20 \%$ showed coarse nuclear chromatin.

The mid-piece area of spermatozoa contained either vesicles of various sizes (Pl. 2, Fig. C) or outer-sheath fibres which continued to the base of the head (Pl. 2, Fig. D). No mitochondria were seen in any of the spermatozoa examined. In the spermatozoa with a large cytoplasmic droplet and no tail, axial-filament fibres as well as outer-sheath fibres, arranged in such a way as to suggest coiling of the tail, were seen within the cytoplasmic droplet (Pl. 2, Fig. E).

Longitudinal and cross-sections through the main-piece showed an increase in diameter due to an excess of outer sheath fibres (Pl. 2, Figs F, G, H and J). In approximately $40 \%$ of the cross-sections through the main-piece, the normal $9+9+2$ axial-filament complex was seen. In the remaining $60 \%$ of the crosssections, the axial-filament complex showed a varied morphology. In the majority, the central two fibres were missing while some had extra inner fibres either enmeshed within the outer-sheath fibres (Pl. 2, Fig. G) or incorporated into the inner nine axial-filament complex. (Pl. 2, Fig. J). Sometimes, extra

\section{EXPLANATION OF PLATE 2}

FIG. A. Light microscope picture of spermatozoa from Patient B showing the typical abnormal morphology. $\mathrm{H}$ and $\mathrm{E}$.

FIG. B. Electron micrograph of spermatozoa from Patient B shadowed with gold/ palladium showing shortened tails with no demarcation between mid-piece and mainpiece.

Frg. C. Longitudinal section of a spermatozoon from Patient $B$, showing an absence of mid-piece morphology which was replaced by vesicles of various sizes.

Fig. D. Longitudinal section through a spermatozoon from Patient B, showing an absence of mid-piece morphology and the outer-sheath fibres appearing to extend to the base of the head.

Fig. E. Longitudinal section through the head of a spermatozoon from Patient B. Note the large cytoplasmic droplet, a coiling of the tail fibres and absence of mitochondria.

FIG. F. Longitudinal section through the main-piece of a spermatozoon from Patient B. showing an increase in its diameter due to an excess of outer-sheath fibres.

Fig. G. Gross section through the main-piece of a spermatozoon from Patient B, showing the thickened outer sheath, absence of the central two fibres and extra fibres enmeshed within the outer sheath.

FIG. H. Cross-section through the main-piece of a spermatozoon from Patient B, showing the thickened outer sheath with an abnormal $11+2$ axial filament as well as extra fibres enmeshed within the outer sheath.

FIg. J. Cross-section through main-piece of a spermatozoon from Patient B, showing the thickened outer sheath, absence of central two fibres and extra fibres present showing an $11+0$ configuration. 
fibres were seen enmeshed within the outer sheath as well as incorporated into the inner axial-filament complex (Pl. 2, Fig. H).

Polymorphonuclear leucocytes, some of them containing phagocytosed abnormal spermatozoa (Pl. 3, Fig. D), were present in all specimens examined from this patient.

Electron microscopy of the testis was carried out on a piece of tissue which was originally prepared and embedded in paraffin wax for routine histology but was subsequently processed and embedded in Araldite. Despite the poor quality of material, thickened tails with extra outer-sheath fibres as well as absence of mitochondria were observed (PI. 3, Fig. C).

\section{DISGUSSION}

The normal ultrastructure of human spermatozoa is now well documented (Schnall, 1952; Anberg, 1957; Fawcett, 1958; Bedford, 1967; Pedersen, 1969), but only a few patients with specific ultrastructural defects which appear to affect fertility have been described (Kagan, 1963; Pedersen et al., 1971; Ross et al., 1971). This may be due in part to the variable proportion of morphologically abnormal spermatozoa present in the human ejaculate which makes it difficult to recognize specific defects in human spermatozoa unless they are present in a high proportion of the sperm population.

The two patients reported here had abnormalities of the outer-sheath fibres and the mid-piece affecting almost all the spermatozoa, and had, in addition, abnormalities of the axial-filament complex and head in a high proportion of the spermatozoa.

The diameter of the tail in the abnormal spermatozoa from both patients was increased due to an excess of outer-sheath fibres. This abnormality was seen in spermatozoa in the testis of both men indicating that this defect was present during the maturation of the spermatozoa within the seminiferous tubules.

In Patient A, normal mitochondria were seen in all the maturing spermatids. The absence of mitochondria and the shortened mid-piece in the majority of spermatozoa must therefore be due to a defect in the formation of the midpiece at a later stage of maturation. The central two fibres of the axial-filament complex were missing in spermatozoa both in the ejaculate and in the testis, again indicating that this defect originated while the spermatozoa were in the seminiferous tubules.

In Patient $\mathrm{B}$, abnormal mid-piece morphology was seen both in ejaculăted and testicular spermatozoa, again indicating that this defect originated during maturation of the spermatozoa. The alteration in arrangement and number of fibres in the axial-filament complex noted in ejaculated spermatozoa could not be seen in the testicular material because of its poor quality.

In Patient $\mathrm{B}$, phagocytosis of the abnormal spermatozoa by polymorphonuclear leucocytes might be a process by which abnormal spermatozoa are removed. Phagocytosis of spermatozoa by polymorphonuclear leucocytes has been seen in $15 \%$ of the semen specimens from men attending a subfertility clinic (A. Ross, unpublished data). 
PLATE 3

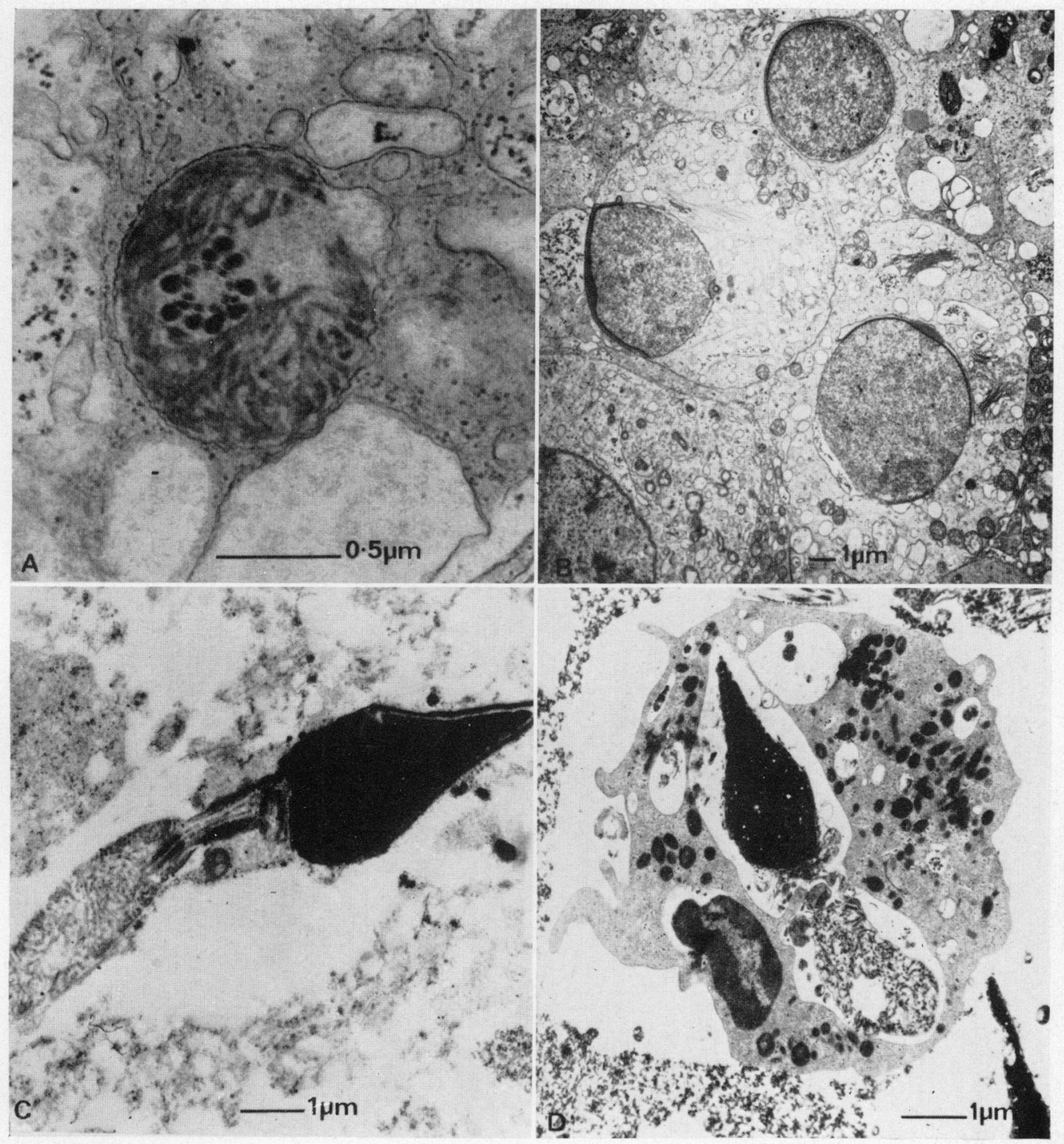

Fig. A. Cross section through the main piece of a spermatozoon in the testis from Patient $\Lambda$, showing an increase in outer-sheath fibres and an absence of the central two fibres. FIG. B. Section of spermatids in the testis from Patient $A$, showing the acrosomal formation and presence of mitochondria which do not contain electron-dense bodies. FIG. C. Longitudinal section through the head and mid-piece area of a spermatozoon from Patient B, showing an increase in outer-sheath fibres and an absence of mitochondria. FIG. D. Polymorph with a phagocytosed abnormal spermatozoon from Patient $\mathrm{B}$, showing the thickened tail with extra outer-sheath fibres. 
Both the patients reported here had a number of spermatozoa with coarse granulation of their nuclear chromatin, suggestive of immaturity (McCosker, 1969). The presence of immature spermatozoa in the ejaculate could be due to a maturation arrest or to the ejaculation of spermatozoa before they had completed maturation in the seminal vesicles.

The percentage of spermatozoa with degenerate or absent acrosomes was higher than in spermatozoa of other men attending a subfertility clinic (A. Ross, unpublished data). Nevertheless, many of the spermatozoa still had a normal head morphology.

There is evidence in animals that the presence of a large proportion of spermatozoa with a specific abnormality is inherited. However, in the majority of reported cases the mode of inheritance is not clear because of the small numbers of animals or relatives of the affected animals which had been investigated.

Donald \& Hancock (1953) found the knobbed acrosomal defect in seventeen sterile Fresian bulls. These bulls were related, and the authors suggested that the condition was the result of a single autosomal recessive gene which has no effect on the females. A similar knobbed acrosomal defect has been observed in a family of British Large boars (Bishop, 1972). In this case, a dominant gene carried by mother and sister which does not affect the females is believed to be responsible. However, Wohlfarth (1961) observed a similar knobbed acrosomal defect in boars, all five full brothers being affected which does not suggest recessive inheritance.

Blom (1966) described the 'Dag' defect in two Danish Jersey bulls which were full brothers and the author suggested that this was the result of the specific sire-dam combination used.

The pseudodroplet defect found in five related Fresian bulls was suggested by Blom (1968) to be hereditary. The 'decapitate defect' was found in twelve of eighty-nine sterile Guernsey bulls (Hancock \& Rollinson, 1949), which had a common ancestor but were not closely related. The author stated that there was no conclusive evidence that the defect was inherited. Jones (1962) described seven related bulls suggesting that the abnormality might be hereditary. Van Rensburg, Van Rensburg \& de Vos (1966), in South Africa found this defect in eight closely related Guernsey bulls, which they thought might be attributed to a recessive hereditary factor.

Clear evidence that infertility due to abnormal spermatozoa can occur as an inherited condition in mice was presented by Rajasekarasetty (1954). $\mathrm{He}$ found abnormalities of the spermatozoa in mice, with a combination of two mutations at the $\mathrm{T}$ locus which, when present singly, did not affect fertility.

In the patients described here, no information is available on the sperm morphology of other members of their family. Therefore, we are not able to show whether or not the abnormalities described above are inherited.

In both patients, the abnormality appears to produce sterility as no evidence of conception has been recorded in the patients' wives. It is worthy of note, however, that Smith, Aura \& Zamboni (1970) showed that immotile spermatozoa in mice, with ultrastructural defects of the tail and normal heads, were capable of fertilizing ova in vitro. 
We have examined spermatozoa by light microscopy from 1000 males attending a subfertility clinic. The two patients described here, together with the one reported previously (Ross, et al., 1971), are the only patients who were found to have an ultrastructural abnormality affecting nearly all their spermatozoa and which was initially detected by light microscopy. This suggests that such abnormalities are found in approximately $0.3 \%$ of all males attending a subfertility clinic.

\section{ACKNOWLEDGMENTS}

The authors are grateful to Dr N. MacLean for the histological studies on the testicular biopsies, Dr P. A. Jacobs for her invaluable discussion and advice in preparing this paper, $\mathrm{Dr} \mathrm{A}$. Chandley for the meiotic preparations and $\mathrm{Mr}$ A. R. Ross, Mrs Lily Gowans and Mrs E. Hunt for technical assistance.

\section{REFERENCES}

Anberg, A. (1957) The ultrastructure of the human spermatozoon. Acta obstet. gynec. scand. Suppl. 2, 1. Aughey, E. \& ReNTon, J. P. (1971) Ultrastructure of abnormal spermatozoa in a stud dog. F. Reprod. Fert. 25, 303.

BANE, A. (1961) Acrosomal abnormality associated with sterility in boars. IVth Int. Congr. Anim. Reprod., The Hague, 4, 810.

BEDFord, J. M. (1967) Observations on the fine structure of spermatozoa of the bush baby, Galago senegalensis, the African green monkey, Cercopithecus aethiops and man. Am. F. Anat. 121, 443.

Bishop, M. W. H. (1972) Genetically determined abnormalities of the reproductive system. F. Reprod. Fert. Suppl. 15, 51, quoting from Madden, D. H. L. (1964) Report concerning the suspected hereditary nature of a spermatozoal defect causing low fertility in boars. Part II. Unpublished report to the Pig Industry Development Authority, London.

Blom, E. (1959) A rare sperm abnormality, 'corkscrew sperms' associated with steritity in bulls. Nature, Lond. 182, 1280.

Bцом, E. (1966) A new sterilizing and hereditary defect (the Dag defect) located in the bull sperm tail. Nature, Lond. 209, 739.

BLom, E. (1968) A new sperm defect, 'pseudodroplet' in the middle piece of the bull sperm. Nord. VetMed. 20, 279.

Blom, E. \& BIRCH-ANDERsen, A. (1962) Ultrastructure of sterilising 'knobbed sperm' defect in bull. Nature, Lond. 194, 989.

Blom, E. \& Birch-Andersen, A. (1968) The ultrastructure of the 'pseudo-droplet' defect in the bull sperm. VIth Int. Congr. Anim. Reprod. A.I., Paris, I, 117.

BLom, E. \& Birch-ANDERSEN, A. (1970) Ultrastructure of the decapitated sperm defect in Guernsey bulls. F. Reprod. Fert. 23, 67.

Court Brown, W. M., Buckton, K. E., Jacobs, P. A., Tough, I. M., Kuenssberg, E. V. \& Knox, J. D. E. (1966) Chromosome studies on adults. Eugen. Lab. Mem. 42.

Donald, H. P. \& Hancock, J. L. (1953) Evidence of gene controlled sterility in bulls. F. agric. Sci., Camb. 43, 178.

FAwCETt, D. W. (1958) The structure of the mammalian spermatozoon. Int. Rev. Cytol. 7, 195.

Hancock, J. L. (1953) The spermatozoa of sterile bulls. F. exp. Biol. 30, 50.

Hancock, J. L. \& Rollinson, D. H. L. (1949) A seminal defect associated with sterility in Guernsey bulls. Vet. Rec. 61, 742 .

Jones, W. A. (1962) Abnormal morphology of the spermatozoa in Guernsey bulls. Br. vet. F. 118, 257.

KAGAN, C. A. (1963) Results of the study of the ultrafine structure of human spermatozoa in oligozoospermia and necrospermia. Urologiya, 28, 34.

Koefoed-Johnsen, H. H. \& Pedersen, H. (1971) Further observations on the Dag-defect of the tail of the bull spermatozoon. F. Reprod. Fert. 26, 77.

MCCosker, P. J. (1969) Abnormal spermatozoan chromatin in infertile bulls. F. Reprod. Fert. 18, 363.

Pedersen, H. (1969) Ultrastructure of the ejaculated human sperm. Z. Zellforsch. mikrosk. Anat. 94 (4), 542.

Pedersen, H., Rebbe, H. \& Hammen, R. (1971) Human sperm fine structure in a case of severe asthenospermia-necrospermia. Fert. Steril. 22, 156. 
RajasezarasetTy, M. R. (1954) Studies on a new type of genetically-determined quasisterility in the house mouse. Fert. Steril. 5, 68.

Ross, A., Christie, S. \& KerR, M. G. (1971) An electron microscope study of a tail abnormality in spermatozoa from a subfertile man. F. Reprod. Fert. 24, 99.

Schnalt, M. D. (1952) Electronmicroscopic study of human spermatozoa. Fert. Steril. 3, 62.

SurTh, D. M., OURA, C. \& ZAMBON, L. (1970) Fertilizing ability of structurally abnormal spermatozoa. Nature, Lond. 227, 79.

Van Rensburg, S. W. J., Van Rensburg, S. J. \& de Vos, W. H. (1966) The significance of the cytoplasmic droplet in the disintegration of the semen in Guernsey bulls. Onderstepoort 7. vet. Res. 33, 169.

Wohloarth, E. (1961) Beitrag zum Akrosom-Defekt im Ebersperma. Zuchthyg. FortpfStör. Besam. Haustiere, 5, 268. 